\title{
INVENTORY OF IRRIGATED RICE ECOSYSTEM USING POLARIMETRIC SAR DATA
}

\author{
Srikanth P*, Ramana K V, Shankar Prasad T, K K Choudhary , Chandrasekhar K, Seshasai MVR and Behera G \\ ASAG, RS\&GIS (AA), NRSC, Balanagar, Hyderabad, 500625 \\ *srikanth_p@nrsc.gov.in
}

KEY WORDS: Polarimetric SAR, Freeman and H-A- $\alpha$ decomposition, Wishart classification, rice and cotton crops

\begin{abstract}
An attempt has been made in the current study to assess the potential of polarimetric SAR data for inventory of kharif rice and the major competing crop like cotton. In the process, physical process of the scattering mechanisms occurring in rice and cotton crops at different phonological stages was studied through the use of temporal Radarsat 2 Fine quadpol SAR data. The temporal dynamics of the volume, double and odd bounce, entropy, anisotropy, alpha parameters and polarimertic signatures, classification through isodata clustering and Wishart techniques were assessed. The Wishart $(\mathrm{H}-\alpha)$ classification showed higher overall as well as rice and cotton crop accuracies compared to the isodata clustering from Freeman 3-component decomposition. The classification of temporal SAR data sets independently showed that the rice crop forecasting can be advanced with the use of appropriate single date polarimetric SAR data rather than using temporal SAR amplitude data sets with the single polarization in irrigated rice ecosystems
\end{abstract}

\section{INTRODUCTION}

In India, rice is grown under diverse agro-ecological conditions and Irrigated rice ecosystem contributes about $45 \%$ to the rice cropped area. Hence, monitoring of these ecosystems in timely and efficient manner is very important for agriculture, environmental sustainability, food and water security. Multispectral data from IRS series of satellites have been effectively used in India for crop inventory but its use is limited for kharif rice due to non-availability of sufficient cloud free data. In this context, microwave remote sensing offers great potential for monitoring crops especially during the monsoon season due to capability of radar systems to acquire data under all weather conditions.

Studies conducted in India and elsewhere have shown the potential of radar remote sensing techniques to crop management (Macelloni, 2002; Brown et al 1999; and Shao Yun et al, 2001). Further, studies conducted in India have demonstrated the utility of temporal SAR data for rice crop monitoring. Temporal SAR data sets of amplitude component are being used to monitor the paddy crop (Panigraphy et al, 1999, and Chakraborty et al, 2005). Research has demonstrated that the additional polarizations will increase the information content in a SAR dataset similar to using multispectral approaches in the optical region (Mc Narain and Brisco, 2004, Feilong et al, 2005). The multi-polarized configurations provide more information related to crop structure and condition. The phase and polarimetric parameters does help in understanding the different scattering mechanisms from different surface features in general and crops in particular. The objective of the current study is to assess the potential of fully polarimetric data for inventory of irrigated rice ecosystem.

\section{METHODOLOGY}

The fine quadpol data from RADARSAT- 2 covering Guntur $\left(2^{\text {nd }}\right.$ and $26^{\text {th }}$ October and $19^{\text {th }}$ November, 2010 with incidence angle $\left.34.12^{0}\right)$ and Anantapur test sites $\left(22^{\text {nd }}\right.$ October, 2010 with incidence angel of $24.5^{\circ}$ ) of Andhra Pradesh were used. The rice and cotton crops are the major crops grown in irrigated and rainfed regions respectively in the Guntur test site. While, the Anantapur test site covers only rainfed areas and the rice crop grown is confined to narrow valley regions where ground water is available for irrigation. Synchronous ground truth data like crop type, phenology, leaf area, plant height, fresh biomass and soil moisture were collected from the test sites on the day of data acquisition.

PolSARPro and ENVI s/w were used for processing of the data sets. The raw data was imported into the coherence matrix as well as amplitude format. The data was geometrically corrected using the GCP's given in the header file using ASF s/w module. The Gaussian-Boxcar Speckle filter with $5 * 5$ size was applied to remove the speckle. The Entropy-Anisotropy-Alpha (H-A- $\alpha$ ) (Cloude and Pottier, 1996) and Freeman 3-component (VolumeOdd-Double) decomposition (Freeman and Druden, 1998) technique was applied on the polarimetric SAR data. The Wishart $(\mathrm{H}-\alpha)$ classification algorithm was implemented on the (H-A- $\alpha)$ decomposed image, while isodata clustering was performed on Freeman 3-component decomposition image. The results were compared with the ground data collected synchronous to the date of pass.

\section{RESULTS AND DISCUSSION}

The incoherent decompositions methods viz. Freeman 3 component and $(\mathrm{H}-\mathrm{A}-\alpha)$ were applied on the speckle filtered data sets (Fig 1). The Freeman decomposition models the coherence matrix as the contribution of three scattering mechanisms, i.e. volume, double bounce and odd bounce scattering. It can be observed from the figure that the rice crop occurring in the eastern part of the image in peak vegetative stage is showing a mix of volume and double bounce scattering mechanisms. While, the 
cotton crop in its early vegetative stage, is depicting a mix of volume and odd bounce mechanism. The Entropy-AnisotropyAlpha $(\mathrm{H}-\mathrm{A}-\alpha)$ decomposition is based on the eigen decomposition of the coherency matrix.

The figure 1, depicts that the mean alpha $(\alpha)$ angle of the rice area is more than the cotton crop and the same is also shown in the scatter plot of alpha for paddy and cotton crops (fig 2). The polarimertic signatures of rice and cotton crops were shown in the figure 3 in the mesh form. The alpha for the rice crop is always found to be higher than for the cotton crop throughout the period of study, which can be exploited for discrimination of cotton and rice crops. The figure $4 \mathrm{a}$ depicts the temporal dynamics of mean volume, double and odd bounce values from the Freeman 3 component decomposition and the figure $4 \mathrm{~b}$ represents the dynamics of $\mathrm{H}-\mathrm{A}-\alpha$ derived from the $\mathrm{H}-\mathrm{A}-\alpha$ decomposition technique.

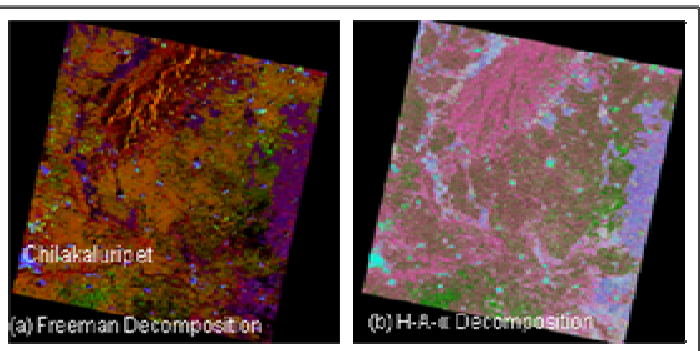

Fig 1. FCC images of Freeman (a) and H-A- $\alpha$ (b) decomposition

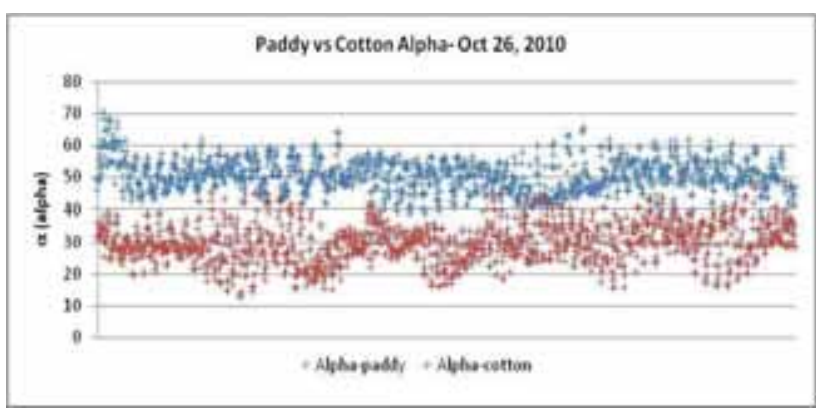

Fig 2. Scatterplot of Alpha for cotton and Paddy crops

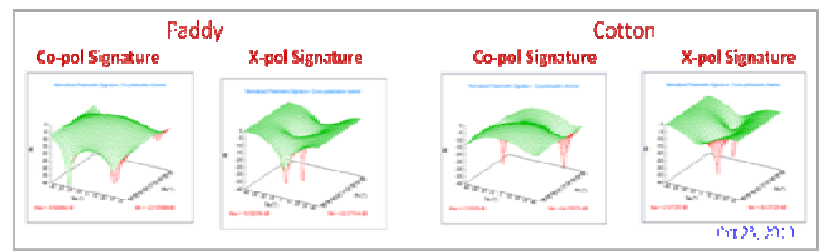

Fig 3. Polarimetric signatures for Paddy and Cotton crops.

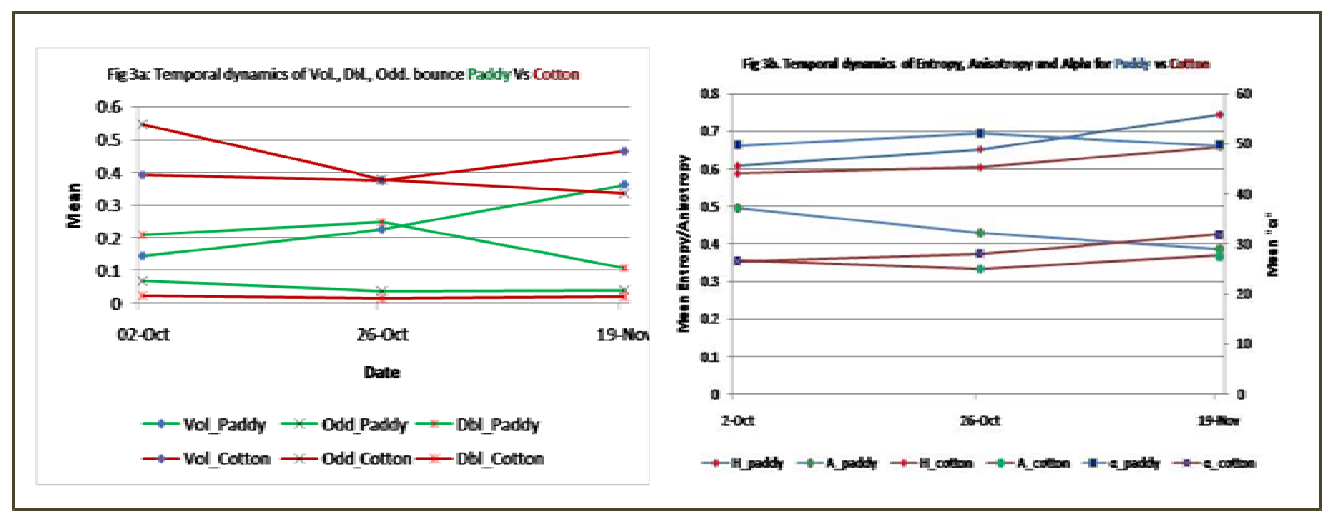

Fig 4. Temporal dynamics of scattering mechanisms and H-A- $\alpha$ parameters

It was observed in cotton initially, the odd bounce mechanism is predominant and with the increase in leaf area and biomass, an increase in the volume scattering has been observed, while there is no significant change in the double bounce scattering mechanism. In the case of rice crop whose leaf orientation is vertical, there has been a significant increase in volume scattering followed by double bounce scattering mechanism. The analysis of the temporal behaviour of the parameters - Entropy, Anisotropy and mean alpha $(\alpha)$ angle generated through the H-A$\alpha$ decomposition showed that the mean alpha $(\alpha)$ is always higher for the paddy crop compared to cotton, entropy is increasing both for cotton and rice crop with the age of the crop, and the anisotropy has decreased from the Oct 02 , to Oct $26^{\text {th }}$ in the paddy crop and is higher than the cotton crop.

Subsequently, the freeman and H-A- $\alpha$ decomposed data sets were subjected to classification and were shown in figure 5. The Wishart $(\mathrm{H}-\alpha)$ classifier achieved the highest classification accuracy for rice and cotton crops. For rice crop, it is observed that using single date data, paddy crop can be classified with more than $94 \%$ accuracy (Table 1) in all the dates and both the test sites studied. 


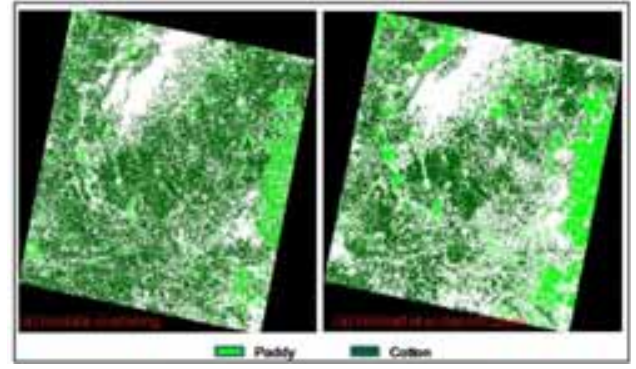

Fig 5. Classified image of Rice and Cotton
While, the cotton crop could be delineated with more than 87.5 percent accuracy and the highest accuracy was achieved in the month of November when the crop attained maximum vegetative cover. The higher accuracy with Wishart classifier could be mainly because, the coherence matrix derivable from Polarimetric SAR data nearly follows Wishart distribution and uses the whole Polarimetric information. Chen et al. (2007) also observed that Wishart classifier has achieved the best classification performance for rice class ranging from 62 to $92 \%$ using a multi temporal dual polarization sets.

\begin{tabular}{|c|c|c|c|c|c|c|}
\hline & \multicolumn{3}{|c|}{ Wishart $(H-\alpha)$ classification } & \multicolumn{3}{|c|}{$\begin{array}{l}\text { Isodata clustering on Freeman } \\
\text { 3-component decomposition }\end{array}$} \\
\hline & $\begin{array}{l}\text { Rice crop } \\
\text { accuracy \% }\end{array}$ & $\begin{array}{l}\text { Cotton crop } \\
\text { accuracy \% }\end{array}$ & $\begin{array}{c}\text { Overall } \mathbf{K}^{\wedge} \\
\text { statistic }\end{array}$ & $\begin{array}{c}\text { Rice crop } \\
\text { accuracy \% }\end{array}$ & $\begin{array}{l}\text { Cotton crop } \\
\text { accuracy \% }\end{array}$ & $\begin{array}{c}\text { Overall } \mathbf{K}^{\wedge} \\
\text { statistic }\end{array}$ \\
\hline Oct- 02,2010 & 95.7 & 87.5 & 0.809 & 52.11 & 83.33 & 0.411 \\
\hline Oct-26, 2010 & 94.9 & 91.6 & 0.782 & 58.14 & 86.46 & 0.443 \\
\hline Nov-19, 2010 & 95.3 & 93.8 & 0.667 & 37.50 & 91.67 & 0.332 \\
\hline & \multicolumn{6}{|c|}{ Anantapur test site } \\
\hline Oct- 22,2010 & 95.8 & - & 0.896 & 41.67 & - & 0.224 \\
\hline
\end{tabular}

\section{CONCLUSION}

The Wishart $(H-\alpha)$ classification showed higher overall as well as rice and cotton crop accuracies compared to the isodata clustering from Freeman 3- component decomposition. The use of alpha and entropy parameters provide substantial information on the polarimetric properties of a scene and can be used to classify an image in a very simple way. The higher accuracies from Wishart $\mathrm{H}-\alpha$ classification could be mainly because of the use of whole polarimetric information. With the consistent higher rice crop accuracies, the rice crop forecasting can be advanced with the use of appropriate single date polarimetric SAR data rather than using temporal SAR amplitude data sets with the single polarization in irrigated rice ecosystems. For cotton crop, depending upon the crop growth, an early assessment can be made. These studies need to be tested in the rainfed upland rice, other rice ecosystems, as well as upscaling the study to cover large areas.

\section{REFERENCES}

A.Freeman and S. Durden, "A three component scattering model for polarimetric SAR data", IEEE Trans.Geosci. Remote Sensing, vol. 36, no.3,pp.963-973, May 1998.

Brown, R.J., Brisco, B., Leconte, R., Major, D.J., Fischer, J.A., Riechert, G., Dorporal, K.D. , Bullock, P.R., Pokrant, H. and Culley, J. 1999. Potential Applications of RADARSAT data to Agriculture and Hydrology. Can. J. of Remote Sensing, Vol. 19, pp. 317-329.

Chakraborty M., Manjunath, K.R., Panigrahy, S., Kundu, N. and Parihar J.S., 2005. Rice crop parameter retrieval using multitemporal, multi- incidence angle Radarsat SAR data, ISPRS
Journal of Photogrammetry \& Remote Sensing, Vol. 59, pp:310 322.

Chen .E.X., Li.Z.Y., Tan.B.X., Pang.Y., Tian.X. and Li.B.B. (2007). Supervised Wishart classifier for Rice mapping using multi-temporal ENVISAT SAR APS data. Proc. "Envisat Synposium 2007", Montreux, Switzerland 23-27 April 2007 (ESA SP-636, July 2007)

China. Proc. 2005 Dragon symposium "Mid-term Results", Santorini, Greece 27 June - 1 July 2005 (ESA SP-611, January 2006)

Feilong L., W Qinmin, W Xiaoqin (2005). Identification of rice crop using envisat ASAR in fuzhou, Fujian province,

Feilong L., W Qinmin, W Xiaoqin (2005). Identification of rice crop using envisat ASAR in fuzhou, Fujian province, China. Proc. 2005 Dragon symposium "Mid-term Results", Santorini, Greece 27 June - 1 July 2005 (ESA SP-611, January 2006)

Macelloni, G., Palosciaa, S., Pampalonia, P., Ruisia, R., Dechambreb, M., Valentinb, R, Chanzyc, R. and Wigneronc, J., 2002. Active and passive microwave measurements for the characterization of soils and crops. Agronomie 22: 581-586.

Mc NcNarain, H. and B.Brisco (2004). The application of C-band polarimetric SAR for Agriculture: a review. Canadian Journal of Remote sensing. 39: 2343-2351

Panigrahy, S., Manjunath, K.R., Chakraborty, M., Kundu N. and Parihar J. S. 1999, Evaluation of RADARSAT standard Beam data for identification of potato and rice crops in India. ISPRS Journal of Photogrammetry \& Remote Sensing 54: 254 - 262.

S. Cloude, E. Pottier "A Review of Target Decomposition Theorems in Radar Polarimetry", IEEE Transactions of 
International Archives of the Photogrammetry, Remote Sensing and Spatial Information Sciences, Volume XXXVIII-8/W20, 2011 ISPRS Bhopal 2011 Workshop, 8 November 2011, Bhopal, India

ISPRS Archives XXXVIII- 8/W20; Workshop Proceedings: Earth Observation for Terrestrial Ecosystems

Geoscience and Remote Sensing, Vol.34, No.2, pp. 498-518, March 1996.

Shao Yun, Chen, J., Guo, H. and Hui Lin, 2004, the potential of Envisat-ASAR data in monitoring crop growth, In Pro. of the Envisat \& ERS Symposium (ESA SP-572), Austria, 6-10 September-2004.

\section{ACKNOWLEDGEMENT}

The authors are grateful to Dr V K Dadhwal, Director, NRSC for providing necessary facilities to carry out the research work under the RISAT utilization programme. 